\title{
One Village One Product (OVOP) in Japan to One Tambon One Product (OTOP) in Thailand: Lessons for Grass Root Development in Developing Countries
}

\author{
Nguyen Thi Anh Thu \\ Chulalongkorn University, Bangkok, Thailand \\ Hue College of Foreign Languages, Vietnam \\ nguyenthianhthu270189@gmail.com
}

\begin{abstract}
Following the 1997 Asian Financial Crisis, Thailand's economy which did rely on external capital and resources suffered from an imbalanced economic growth. As a solution to the economic restructuring process, endogenous development concept proved to be an alternative development paradigm which prioritizes the community development, human empowerment in the transformation of local resources. Accordingly, One Tambon One Product (OTOP) was designed to unlock grass-root potentials by generating income through developing local products in a national, regional, and global scale. This initiative was first developed under the name of One Village One Product (OVOP) by local people in the poorest Oita Prefecture, Japan in 1961. The aim of the paper is to compare two development models of OVOP and OTOP. The comparative study draws useful lessons from the experience of OTOP for future applications of the OVOP model in developing economies. The paper finds that there are inevitable differences in terms of administration, finance management, human resource management, and marketing promotion management between bottom-up OVOP in Japan and top-down OTOP because of social diversity, political culture, and economic capability in Thailand. The paper contributes to provide a comparative study into models of sustainable development in the context of increasing gap between the urban and rural in globalization.
\end{abstract}

Keywords: OVOP, OTOP, sustainable endogenous development, regional growth, grass-root

\section{Introduction}

Rapid industrialization and modernization so far has helped Thailand achieve high GDP, and also brought some undesired consequences. The Human Development Report of Thailand accounts that the inequalities in wealth distribution among different groups, internal immigration from rural to urban areas emerge as critical problems in the country (Kuhonta, 2003). Following the 1997 Asian Crisis, the expanding gap between the rural and the urban drives the social movement such as Assembly for the Poor (Missingham, 2003). Therefore, the government paid more attention to rural development by setting sustainable development as one of the targets in National Development Plan (National Sustainable Development Strategy, 2008). One of the solutions is One Tambon One Product (OTOP) project which derived from One Village One Product (OVOP) in Japan. OVOP features a small-scale production in local districts and aims to generate income to villagers by distributing nationally and globally their products. In the context of global restructured economy, this initiative deserves to be widespread as a model for grass-root and sustainable development. For Thailand, in awareness of its imbalanced economy, in terms of sectors and geographical regions, this policy serves as a solution to sustainable economic development.

The objectives of this paper are first to compare the original Japanese OVOP scheme and the Thai OTOP in terms of policy implementation to clarify how the idea of grass-root development has been transferred and modified. The ultimate objective is to extract lessons from the comparison for the future application of the OVOP model in developing countries. With this in mind, three questions are worth of studying: (1) why does the OVOP initiative deserve to be widespread applied as an economic strategy for sustainable development in Thailand and in other countries? (2) How different are OVOP and OTOP model implemented in Japan and Thailand? (3) How are the experiences in implementing OTOP in Thailand relevant to grass-root development in developing countries? The paper argues that there are differences between the original bottom-up OVOP in Japan and the replicated top-down OTOP in Thailand because of some political, economic and social factors. These differences are also expected in carrying out OVOP in other developing countries. In 
order to make OVOP take off in developing countries, it is necessary to consider that lessons drawn from the transfer from OVOP in Japan into OTOP in Thailand.

\section{Literature Review}

Endogenous Development: Resource Economy in the Third world undoubtedly results in the deterioration of local cultural, political, and economic system, limiting opportunities for marginalized groups. In a recent report by World Bank, the present production-oriented capitalism needs to re-identify and prioritize its goal for a sustainable economy ${ }^{1}$ with the participation of social capital, the role of the state, and local government and non-governmental organizations (Nixon, 2009). Moreover, in the Sustainability Revolution, regions need to revitalize low-income groups, understand regional resources ${ }^{2}$, develop potential sectors that bring addedvalue for the region, and enhance human empowerment (Nixon, 2009). These ideas lie in the concept of regional development. In a globalized world, the role of locality and regional development is particularly significant. Concerning the model of regional growth, there are two approaches to regional development in focus: exogenous regional development and endogenous regional development. Originally, the concept of an endogenous model of development appeared in the late 1970s. Unlike exogenous development which relies on external capital and resources to promote industries, endogenous development approach is considered as the alternative development paradigm which places social development, the growth of human capital, the role of local communities and their activities in the transformation of local resources in the center. A characteristics feature of endogenous development is the diffusion of knowledge and innovation within enterprises in a region to make it become a local industry (Wysocka, 2009). Notably, Friedmann (2007) identified seven elements of regional assets necessary for endogenous development, including basic human needs, organized civil society, the heritage of an established environment and popular culture, intellectual and creative assets, regional resource endowment, the quality of its environment, and infrastructure. This kind of regional development gets impetus since Marshall (1948), Schumpeter (1991) and Kirzner (1997) noted that knowledge and rural entrepreneurship are the modern drivers of regional growth. Rural entrepreneurship is given its importance in regional sustainable development, in terms of poverty reduction, and meeting social needs (Bornstein, 2007; Dees, 2007; Torii, 2009; Torii 2010). Community-based enterprise CBEs are a development strategy based on community's resources. Among these resources are social capital, structures, and networks (Torri, 2009, Coleman, 1988; Coleman, 1990) that facilitate the cooperations in CBEs for community development (Kilkenny et al., 1999; Lyons, 2002). OVOP is a shining example of the endogenous development and rural entrepreneurialism.

History of OVOP: The One Village One Product (OVOP) movement was initiated in 1961 by local residents in Oyama town, Oita prefecture, Japan (Igusa, K. nd). Oyama, located in hilly town, is the poorest town in Oita Prefecture. Because rice planting is not a sustainable livelihood, the challenge for Oyama was the migration of the young people who had to be woodcutters or seasonal migrant laborers for higher income in cities. The villagers were aware that the hilly geography was not suitable for mass cultivation of rice (Wahlin and Natsuda, 2008). They decided not to follow the rural development policy of the Japanese Government, which relies on subsidies and rice cultivation. In order to deal with local depopulation, Mr. Yahara, the mayor of Oyama Town, the president of the Oyama agricultural cooperative decided to be self-reliant by utilizing social capital and local knowledge for community development (Pitchayapisut, 2008). He launched a New Plum and Chestnut (NPC) strategy which aimed at transforming local agricultural production from rice into more promising plums and chestnuts. They were convinced that the investment in chestnut will allow them to lighten their workload, and work on other tasks to complement income from harvesting. The movement which then was transformed into Neo Personality Combination in 1965 and New Paradise Community in 1969 contributed to improve the quality of life and decrease youth from leaving the town of Oyama. Subsequently, the OVOP movement was launched across prefecture by Governor Dr. Morihiko Hiramatsu in 1979. OVOP Movement has spread to other rural Japanese areas that fall behind in its economic development

1There has generally been recognition of three aspects of sustainable development: Firstly, an economically sustainable system must be able to produce goods and services on a continuing basis, to maintain manageable levels of government and external debt, and to avoid extreme sectoral imbalances which damage agricultural or industrial production. Moreover, an environmentally sustainable system includes maintenance of biodiversity, atmospheric stability, and other ecosystem functions are not economic resources. Finally, a socially sustainable system must achieve distributional equity, adequate provision of social services including health and education, gender equity, and political accountability and participation.

2Known as "resources metabolism" 
and face the problem of out-migration and an aging population (Figure 1).

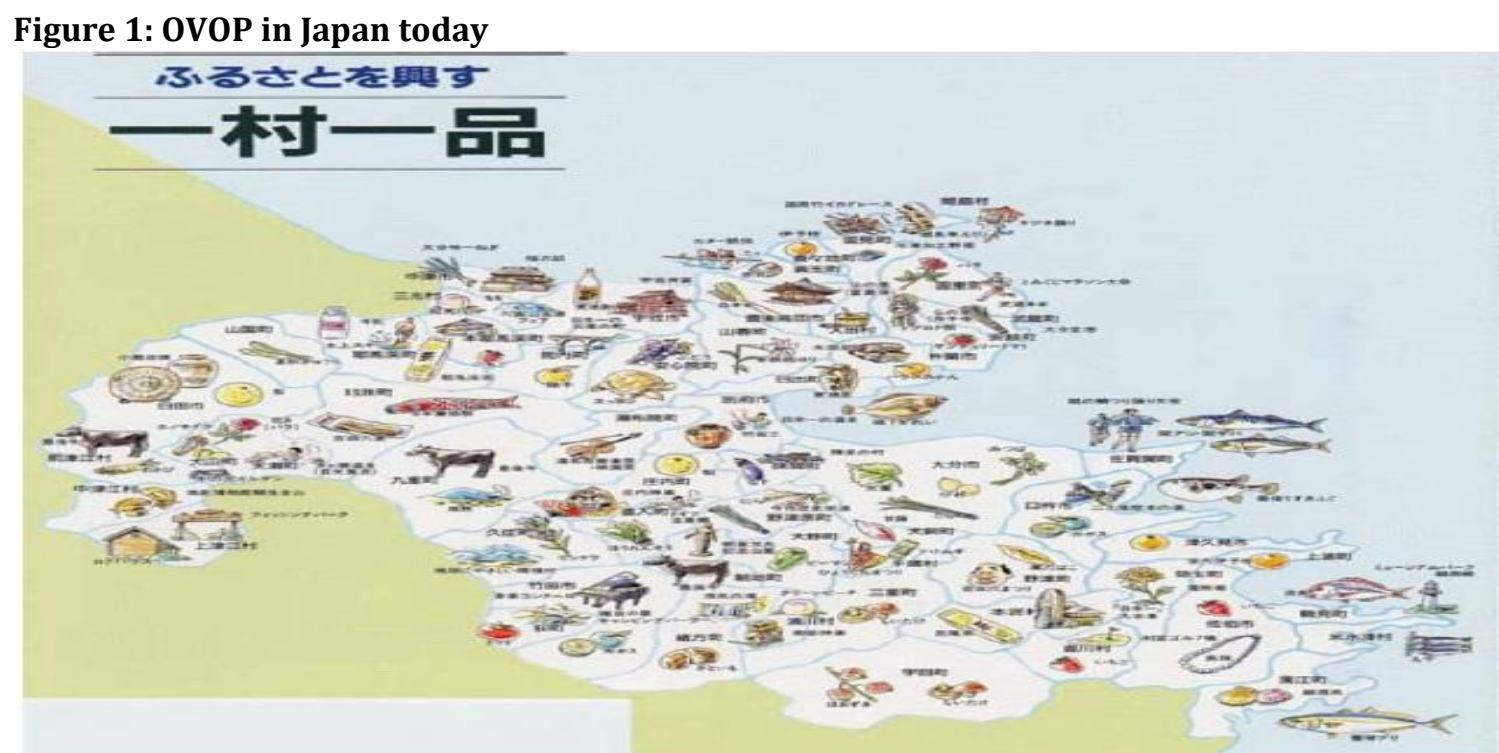

Source: Oita Prefecture International Center

Principles of OVOP: According to Hiramastsu (2008), the operation of OVOP movement is based on the following four principles (Figure 2).

- Think Globally, Act Locally: Local residents are expected to create global products that embody cultural richness and natural resources. Such local flavor adds value to local products while the use of local human makes economic activities sustainable.

- Self-reliance and creativity: local people play a central role in selecting products to develop, raising capital being accountable for the production process, and improving individual creativity.

- Capacity building for human-resource: In this sense, local people are to re-value and re-invent their local resources and cultural craftsmanship to cultivate a distinctive product in agriculture, tourism, trading, etc. The expected products are not only physical products but also entrepreneurs with leadership in some fields.

These core elements have been changed in its transfer to Thailand.

Figure 2: Three Principles of OVOP

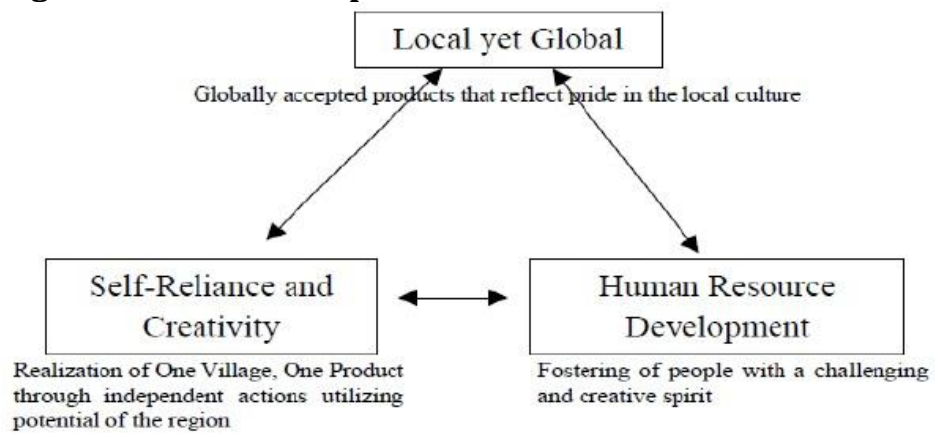

Source: $h t t t p: / / w w w . o v o p . j p / e n / i s o n \_p$

Thailand's New Economic Situation: Before 1997, for many years, Thailand relied on mass production to drive exports and attract FDI. Hence, Thailand enjoyed being one of the leaders in Asian Miracle, with real annual GDP growth averaging about 9.5 percent between 1988 and 1996 (Shinawatra, 2005). However, this results in unsustainable and imbalance growth. Thailand's economy is highly vulnerable to external shocks. Many years after 1997, Thailand was still struggling to recover from the 1997 financial crisis that had 
devastated many economies and had profound impacts on Thailand export and import. Additionally, internal immigration as well as wealth gap which are consequences of imbalanced investment between urban and rural areas is a sizeable challenge for Thailand. The urgent needs for the new government are to create unique value for Thai economy. In other words, Thailand needed to transform it into a knowledge-based economy in steps with global trend. Also, it needs to rely on self- sufficiency by investing in its own strength, resources, and assets, instead of being dependent on foreign trade, FDI and vulnerable to external shocks as before. The vision of building an internally resilient and externally competitive economy is the solution for Thailand's renaissance following the stagnation in 1997. OTOP was the initiative in the Dual Track policy, a package of innovative and integrated measures by former Prime Minister Thaksin Shinawatra when he was first in power to fulfill these two goals (Shinawatra, 2005). Aiming at rural empowerment, OTOP is developed on the foundation of the endogenous development. However, OTOP witnesses some differences from its original OVOP model which are addressed in the next section.

\section{Methodology}

This qualitative paper draws on documentary review, historical narratives of the development of OVOP in Japan and OTOP in Thailand. Comparison is adopted as an effective method to provide critical analysis of implementation of the two policies in different context.

\section{Results and Discussion}

Although the scheme of OVOP and OTOP are conducted for similar objectives, there are still some differences in their implementation.

Initiative and Administration: The basic philosophy of the OVOP movement is to mobilize local human and material resources to create value-created goods and services. However, this purpose was changed in OTOP project to fulfill different stages of Thailand's economic development. For the Oita OVOP movement, the purpose was to revitalize local communities left behind in the nation's economic development process and to solve the depopulation. The Thai OTOP is implemented as a national policy; hence, it is much more attached to the aim of national economic restructuring after the Asian crisis. It is also pointed out that Thai OTOP is a top-down scheme directed by the central government while the Japanese OVOP is bottom-up initiated by communities with support of local government (Fujioka, 2006). In Oita, OVOP is a truly local development policy. It was Mr. Harumi Yahata, the former-mayor of the village and the president of the Oyama Village agriculture cooperative, who had an insight of the local geography and poor situation, spent a long time exploring a new way to maximize local resources to increase local people's income in a sustainable way (Pitchayapisut, 2008). Central government support comes in form of basic physical infrastructure to provide energy, water, materials, buildings, and mobility to facilitate economic efficiency of the project. This ultimately illustrates the core role of the local element in endogenous development theory discussed in the last section (Figure 3).

\section{Figure 3: Oita's OVOP Administrative Structure}

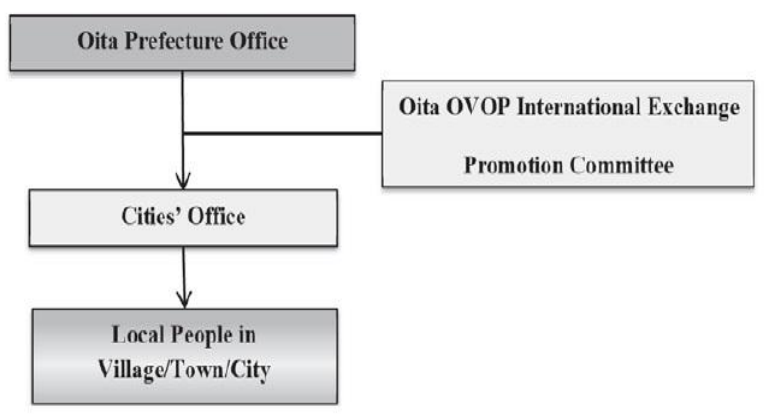

Source: $h t t t p: / / w w w . o v o p . j p / e n / i s o n \_p$

On the other hand, since OTOP is adopted as a national policy under the control of Ministry of Interior, OTOP 
was implemented by three administrative levels. First, local product is initiated by local sub-committeeTambon Administration Organization TAO. The provincial and district OTOP Committee headed by governor and district major will integrate it into provincial plan and budget lines and developing product quality (JICA 2003, chapter 2/16). The OTOP office and "National One Tambon One Product Administrative Committee" is responsible for planning strategy, setting the standards, and engaging the participation of local government (Kurokawa, et al., 2010). The three-layer administration means that OTOP is created not only by local people and local government but also by governmental agencies. The necessary qualifications to participate in OVOP are also different in each case. In Japan, there are none. OVOP programs are open to local residents' initiatives. In contrast, it is required to register with the local OTOP sub-committee. Hereby, OTOP violates fundamental points in the OVOP movement, making OTOP not a truly regional endogenous development policy.

\section{Figure 4: Thailand's OTOP Administrative Structure}

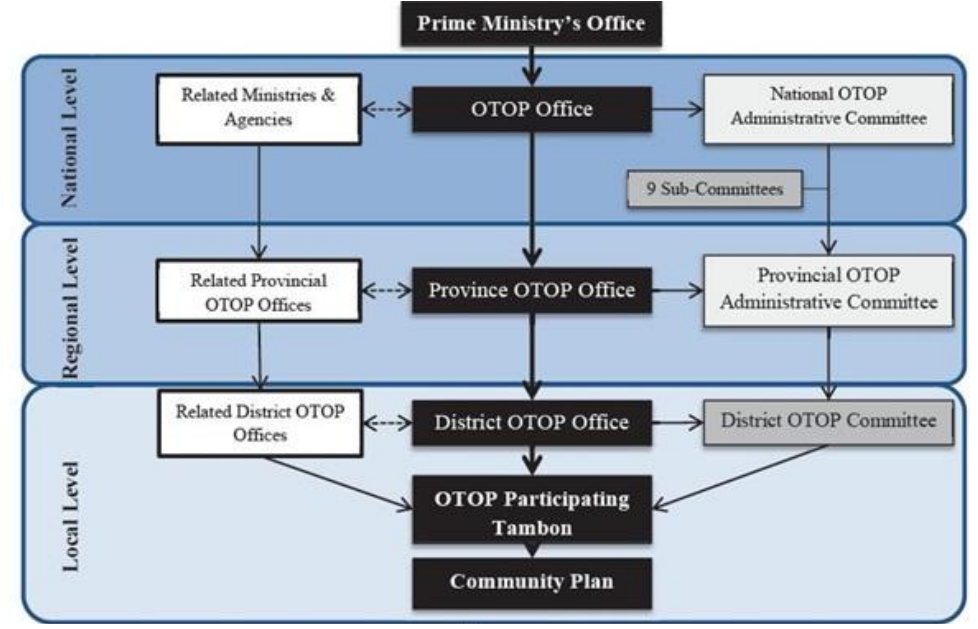

Source: Regulation of the Office of Prime Minister on National OTOP Committee (No.2) B. E. 2002

Nevertheless, it should be noted that there are some political dimensions to justify the central role of Thai government in OTOP program. On the one hand, in Japan, the Oita movement was an endogenous one without any precedent and the prefectural government independently developed it. For Thailand, the success of the replicated model depends on whether the central government had the capacity to sustain it. The problem emerges because local governments in Thailand cannot replace the central government when it comes to the limited finance, management to ensure the success of the policy. On the other hand, OTOP is one of pro-poor policies initiated by former Prime Minister Thaksin Shinawatra who aims to exert a greater influence on the rural poor. The basic motivation of the former Prime Minister Thaksin was to get support from the farmers and to show his capacity to foster coordination among government program for Thai people's lives. The success of the policy contributes to the greater approval of the majority in society for his position of the Prime Minister his incoming election victory. Only by top-down mechanism of policy implementation can the result come out quickly and widely.

Human Resource Development: Oita government is fully aware of the double mission of developing physical products and enhancing people's skills and knowledge. Oita local government has a plan to develop entrepreneurship for local people in each community so that some trainees can become future leaders in their communities. It was done by establishing training schools named "Toyo no Kuni Development School" (Pitchayapisut, 2008). The characteristics of the schools depend on the local demand of learning, including Agricultural Training School, a Commerce School, and a Tourism School. The local residents come to class to learn from experienced business owners, or experts in the fields of their products to learn how to create a product, deal with finance, and manage operational activities effectively (Pitchayapisut, 2008). With the same aim of human resources development, Thai government also organizes training for local resident. However, the difference is the training just provides basic vocational knowledge instead of specializing in the local product. Thus, they find the class not much useful for local projects. This is understandable because local 
people are not involved in the selection of trainers. The training is organized by national government who does not understand the demand of local people; thus select the trainers whose knowledge is not applicable in the unique local resources (Kaoru et al., 2011). Consequently, local people find it hard to map their comparative advantage and to empower themselves.

Finance Management: Difference in finance management can be clearly found in two cases. According to the OVOP principle, local people should be self-reliant and creative in generating capital for their projects without national governmental subsidies. However, the budget for the local enterprises in OTOP program comes from governmental special grant. Since 2001-2002, annual grants for OTOP were directly allocated from the Bureau of Budget to related agencies (OSMEP, 2008). Moreover, the Thai OTOP is active in connecting its program with Bank for Agriculture and Agricultural Cooperatives (BAAC) credit in addition to low interest loans from government saving banks and direct government subsidies. BAAC started a new credit scheme (group joint liability credit) when the OTOP program was officially launched. Therefore, local people cannot recognize the importance of their participation in grass-root development, and are not motivated to maximize their entrepreneurship to overcome their poverty. Governmental subsidy does not contribute to empower the rural poor in the long term, but making them more dependent on external financial assistance and less accountable to the project that they themselves initiate in OTOP program.

Marketing Promotion: Marketing assistance is an important area of OVOP activities. In OVOP, it is suggested that local government should provide local people with marketing local products. Firstly, the governor tried to establish local stores, building outstanding view-board to show the products for regional customers. Besides, the image of different kind of local products were displayed everywhere in the town to popularize them. Secondly, the local government attempted to promote its products in a number of foods fairs, luxury restaurants and markets in Tokyo. Last but not least, local products were also advertised on website as another channel to bring local products to international market (Pitchayapisut, 2008). In order to achieve this, the local people emphasized on establishing brand names for local products. The local manufacturers created their own logo with the hope that the brand logos help to deliver the value of local product. The promotion of OTOP products owes much resemblance to OVOP program, mainly through two prominent measures of OTOP brand making using a common logo and Internet marketing ${ }^{3}$ (Community Development Department. 2002). Nevertheless, OTOP was designed to become mass production-oriented rather than regional development-oriented with a series of government-led marketing activities such as the brand marketing strategy for export, OTOP Product Champion (OPC) scheme in 20034, "matching buyers to OTOP producers" in 2007. Interestingly, in the OPC scheme, the 3-star or higher stars manufacturers will be able to access to the so-called "OTOP City" for grant ${ }^{5}$ (Kaoru et al., 2011). Four-star or five-star awardees have better chances of obtaining public subsidies or being sent overseas for training. In this way, OTOP continued to support the advantaged CBEs, and ignored the disadvantaged. These substantial financial supports go a long way in challenging the self-reliance, and sustainability of CBEs towards local development. Also, the OTOP logo was created by the government and five-star goods are promoted for export, rather than reinforcing the pride in local quality.

\section{Conclusion}

It is undeniable that the OVOP model for developing countries is designed to create a unique value for national economy in a globalized and competitive world trade. While the health of the world economy is unpredictable, the idea of grass-root empowerment tends to be a good answer for developing countries to

\footnotetext{
3 Thai Tambon dot com" has been developed jointly by the Ministry of the Interior, Ministry of Commerce, Ministry of Agriculture and Cooperatives, Bangkok Metropolitan Authority, and Internet Thailand, Ltd. This website

(http://www.thaitambon.com/English/AboutTTB.htm) is a non-profit venture which offers information on Tambon based on a large and comprehensive database. The information includes location maps, features of local occupation groups, OTOP products, and links to thousands of export companies. It has introduced e-commerce for OTOP product

${ }^{4}$ Since 2003, individual entrepreneurs, CBEs or SMEs, who are registered as OTOP manufacturers, are entitled to participate in the OPC contest. In this contest, OTOP registered products are graded from 1-star (the lowest) to 5- star (the highest) certificated products by an independent committee. The assessment criteria emphasizes: i) export potential through strong brand capacity; ii) stability and production sustainability and stability of quality; iii) level of consumer satisfaction; and iv) the background of the product, particularly the use of locally available resources, knowledge and culture.

5Under this scheme, 3 -star producers can access a maximum amount of 500,000 baht. By the same token, 4-and 5-starts

producers can obtain a maximum amount of 750,000 and 1,000,000 baht, respectively
} 
strive on its inner strength and to be less vulnerable to external factors. As soon as regional assets are prepared, rural entrepreneurialism can promote sustainable regional development, in terms of the revitalization of rural society, reduction of income gaps, alleviation of poverty, and expansion of employment opportunities. The study also shows that in applying OVOP model, due to political interests of Thai government, and economic incapability of local governments, it is difficult maintain the original principles in the OTOP movement. Therefore, there are differences in terms of administration, human resources management, finance management, and marketing promotion between OVOP and OTOP program. For these reasons, in many cases, OTOP project has ended up as nothing more than a government-led project for the manufacturers of new local specialties. The findings and arguments in the paper so far contribute to prove the hypothesis that there are differences between the original bottom-up OVOP in Japan and the replicated topdown OTOP in Thailand because of some political, economic and social factors. Significantly, it should be noted that these differences are can be found in other developing countries. Therefore, it is necessary to provide suggestions for future applications of OVOP in other developing countries.

\section{Recommendations}

\section{Software (Process)}

Financial Support: In developing countries, it is so difficult for small-scale enterprises in a village to raise an initial investment that they themselves have to prepare or borrow money from their relatives, from moneylenders, loan sharks, and pawn brokers to start their business (Shinawatra, 2005). High interest keeps them in the cycle of debt and poverty. Regarding this, micro financial loan should be used as a way to make sure grass-root finance to be asset-creating rather than debt-generating. When the poor shares risk, they are likely to work harder than if the money were simply handed over as a grant. This is why an integrated portfolio of micro financial grant should be introduced provide "seed money" for the local people.

Production Development: Many developing countries have fallen in line with the model of mass manufacturing, (Shinawatra, 2005). This mass production-based economy and export-led growth strategy is suitable for a development phase of a country which is no longer able to rely on the hand-down industries or low-value manufacturing assembly. Value creation through local highly-quality products tends to be an effective response to challenges of competition in the global trade. Hence, how much emphasis is to be put on export is the question for developing countries. If these questions are not well examined, some developing economy will fall in the trap of mass production-based and export-oriented model of local specialties again.

Hardware (Physical infrastructure): One of the limitations in developing is inadequate transport infrastructure that obstructs local products from participating in national and global value chains. Reportedly, 61 per cent of the world population will live in urban areas by 2030 (UNHABITAT, 2011). Hence, it is recommended that nationwide delivery services and transportation networks need to be expanded and improved.

Heart-ware (People): Because of the short history of decentralization and local government incapacity, the role of central government in developing countries tends to outweigh the local government to ensure the implementation of the national policy of OVOP. From the viewpoint of endogenous development theory, the governmental participation can weaken community's effort, but in some developing countries which are lacking in basic environment for people's initiative as well as the basic structure for community-based movement, the involvement of central government is necessary in budget, human resources, time and other resources in project management. The important point here is the adequate mixture of residents' movement from the bottom and the involvement of government from the top. In order to avoid problem, the policy implementation should be assigned to only one ministry. As in the case of Thailand, central government established OTOP central committee and OTOP coordination office. Four Ministries, namely Ministry of Industry, Ministry of Agriculture and Cooperative, Ministry of Home Affairs and Ministry of Trade were directly participating through five small committees ${ }^{6}$. Close intra-governmental coordination was needed for

${ }^{6}(1)$ Management subcommittee, (2) Marketing subcommittee, (3) Production promotion subcommittee, (4) Product standard and quality development subcommittee, (5) Regional and provincial subcommittee 
a successful mobilization of local human and material resources. Lastly, it is necessary to emphasize the leadership of local people in visions for future development, awareness of local situation, proactive decision. Also, the role of Mr. Harumi Yahata and the former Prime Minister Thaksin is undeniable in promotion of the initiatives. More importantly, it is necessary to keep an eye on political participation, since OVOP movement and regional development can be political tool. Otherwise, the grass-root development turns out to be a short-term policy to gain vote in political game.

\section{References}

Bornstein, D. (2007). How to Change the World: Social Entrepreneurs and the Power of New Ideas (2nd ed.), New York: Oxford University Press.

Coleman, J. S. (1988). Social Capital in the Creation of Human Capital. American Journal of Sociology, 94, 95120.

Coleman, J. S. (1990). Foundation of Social Theory. Cambridge: MA, Harvard University Press.

Dees, G. (2007). Taking Social Entrepreneurship Seriously. Society, 44(3), 24-31.

Friedmann, J. (2007). The Wealth of Cities: Towards an Assets-based Development of Newly Urbanizing Regions. Development and Change, 38(6), 987-998.

Fujioka, R. (2006). Thai OTOP Project: Lights and Shadow of Grassroots Development Policy. Chapter 6, OVOP and Developing countries. Institute of Developing Economies, Japan External Trade Organization (IDEJETRO), ISBN4-258-29003-3

Hiramatsu, M. (2008). One Village, One Product Spreading throughout the World. Oita Japan: Office: Oita OVOP International Exchange Promotion Committee.

Igusa, $\mathrm{K}(\mathrm{n}, \mathrm{d})$. Globalization in Asia and Local Revitalization Efforts: A view from One Village One Product (OVOP). Retrieved from http://www.ide.go.jp/English/Ideas/School/pdf/igusa.pdf

Jonathan, M. H. (2000). Basic Principles of Sustainable Development. Global Development and Environment institute working paper 00-04. Tufts University Medford MA, USA.

Kaoru, N., Kunio, I., Wiboonpongse, A., Cheamuangphan, A., Shingkharat, S. \& Thoburn, J. (2011). One Village One Product- Rural Development Strategy in Asia: The Case of OTOP in Thailand. Ritsumeikan Center for Asia Pacific Studies RCAPS Working Paper, 11 (3). Retrieved from http://www.apu.ac.jp/rcaps/

Kirzner, I. M. (1997). How Markets Work: Disequilibrium, Entrepreneurship and Discovery. London: The Institute of Economic Affairs

Kuhonta, E. M. (2003). The Political Economy of Equitable Development in Thailand. American Asian Review, 21(4), 69-108.

Kilkenny, M., Nalbarte, L. \& Besser, T. (1999). Reciprocated Community Support and Small Town Small Business Success. Entrepreneurship \& Regional Development, 11, 231-46.

Kurokawa, K., Tembo, F. \& Dirk, W. V. (2010). Challenges for The OVOP Movement in Sub-Saharan Africa Insights from Malawi, Japan and Thailand. JICARI Japan International Cooperation Agency Research Institute 18. Retrieved from: http://www.isn.ethz.ch/isn/DigitalLibrary/Publications/Detail/? ots591=0c54e3b3-1e9c-be1e-2c24- a6a8c7060233\&lng=en\&id=116727

Lyons, T. (2002). Building Social Capital for Rural Enterprise Development: Three Case Studies in the United State. Journal of Developmental Entrepreneurship, 7(2), 193-216.

Marshall, A. (1948). Principles of Economics: An Introductionary ( $8^{\text {th }}$ ed). London, Macmillan.

Missingham, B. (2003). Forging Solidarity and Identity in the Assembly of the Poor: From Local Struggles to a National Social Movement in Thailand. Asian Studies Review, 27(3), 317-340.

National Sustainable Development Strategy: A Guidance Manual. (2008). The Office of National Economic and Social Development Board, United Nations Environment Program, and Thailand Environment Institute.

Nixon, J. (2009). Sustainable Economic Development: Initiatives, Programs, and Strategies for Cities and Regions. Urban Sustainability Associates. Sustainable System, Inc.

Pitchayapisut, N. (2008). The Roles of Government and Social Sectors in Local Revitalization in Japan: The Case of Oita's OVOP (One Village One Product). Unpublished Master Thesis, Thammasat University, Thailand.

OSMEP. (2008) OTOP Summary Report 2003-2008. The Office of Small and Medium Enterprises Promotion (OSMEP).

Shinawatra, T. (2005). Empower the Grassroots - Essential Factors for Sustainable Development. Government 
Saving Bank, Bangkok, Thailand.

Schumpeter, J. A. (1991). Essays on Entrepreneurs, Innovations, Business Cycles and the Evaluation of Capitalism. New Brunswick and London, Transactions Publications.

Torri, M. C. (2009). Community Entrepreneurship among Lower Castes in India: A Grassroots Contribution toward Poverty Alleviation and Rural Development under Conditions of Adversity and Environmental Uncertainty. Journal of Developmental Entrepreneurship, 14(4), 413-432.

Torri, M. C. (2010). Community-based Enterprises: a Promising Basis towards an Alternative Entrepreneurial Model for Sustainability Enhancing Livelihoods and Promoting Socio-economic Development in Rural India. Journal of Small Business and Entrepreneurship, 23(2), 237-248.

UNHABITAT. (2011). State of the World's Cities 2010/2011 - Cities for All: Bridging the Urban Divide. Retrieved from http://www.unhabitat.org/pmss/listitemdetails.aspx?publicationID=2917

Wahlin, W. \& Natsuda, K. (2008). One Village One Product: Japan's Rural Entrepreneurial Scheme Goes Abroad. Japan Inc., 75, 60-61.

Wysocka, A. J. (2009). Theories of Regional and Local Development-Abridged Review. Bulletin of Geography Socio-Economic Series, 12, 76-90. 